\title{
Editorial: Multisensory Integration: Brain, Body, and World
}

\author{
Achille Pasqualotto ${ }^{1}$, Magda L. Dumitru ${ }^{2,3 *}$ and Andriy Myachykov ${ }^{4,5}$ \\ ${ }^{1}$ Faculty of Arts and Social Sciences, Sabanci University, Istanbul, Turkey, ${ }^{2}$ Department of Cognitive Science, Macquarie \\ University, Sydney, NSW, Australia, ${ }^{3}$ Cognitive Science Department, Graduate School of Informatics, Middle East Technical \\ University, Ankara, Turkey, ${ }^{4}$ Department of Psychology, Northumbria University Newcastle, Newcastle-upon-Type, UK, \\ ${ }^{5}$ School of Psychology, Centre for Cognition and Decision Making, National Research University Higher School of \\ Economics, Moscow, Russia
}

Keywords: multisensory integration, body representation, attentional deployment, emotional processing, numerical cognition, language, embodied reasoning, time processing

\section{The Editorial on the Research Topic}

\section{Multisensory Integration: Brain, Body, and World}

The brain is safely sealed inside the cranium, with virtually no direct interaction with other parts of the body and the outside world. Nevertheless, it constantly processes the information conveyed by several sensory modalities in order to create representations of both body and outer world and to generate appropriates motor responses (Ehrsson et al., 2005; Farnè et al., 2005; Green and Angelaki, 2010). For example, vision can convey information about dangerous stimuli to trigger the generation of appropriate motor response (e.g., escape, avoidance, fight, etc.). Rather than processing sensory inputs in isolation, the brain integrates sensory information (Stein and Meredith, 1993; Fetsch et al., 2012) by forming reliable and robust representation of the external world and body. For example, when both visual and auditory input inform about the same danger, an appropriate motor response is more rapid and efficient (Sereno and Huang, 2006; Laing et al.).

Until a few decades ago, it was strongly believed that sensory (or multisensory) integration occurred only in high-level/associative areas or the cortex (Ghazanfar and Schroeder, 2006; Pavani and Galfano). Recently, several "new" multisensory areas have been discovered (Gobbelé et al., 2003; Pietrini et al., 2004), suggesting that a larger portion of the cortex is engaged in multisensory processing. Additional evidence suggests that multisensory integration also occurs in sub-cortical areas (Kuraoka and Nakamura, 2007; Amad et al., 2014). Finally, and perhaps surprisingly, some studies have demonstrated that multisensory processing occurs in primary sensory areas that were traditionally considered to be uni-sensory (Zangaladze et al., 1999; Murray et al., 2005).

Theories such as "neural reuse" (Anderson, 2010) and "metamodal" organization of the brain (Pascual-Leone and Hamilton, 2001) attempt to provide new paradigms for brain functioning taking into account widespread multisensory integration. The evolutionary advantage of multisensory integration might be the resulting availability of more reliable representations of the external world and body (Elliott et al., 2010; Grüneberg et al.) based on multiple sensory inputs and the resilience to brain injuries and sensory loss (Sarno et al., 2003; Pasqualotto and Proulx, 2012; Brown et al.; Finocchietti et al.). Indeed, multisensory integration has been reported in various experimental tasks including spatial representation (Pasqualotto et al., 2005), object recognition (Woods and Newell, 2004; Harris et al.; Höchenberger et al.; Laing et al.), movement perception (Grüneberg et al.; Imaizumi et al.; Uesaki and Ashida), body representation (Pasqualotto and Proulx, 2015; Pavani and Galfano; Tajadura-Jiménez et al.; Yiltiz and Chen), emotional processing (Miu et al.; Piwek et al.), attentional deployment (Spence, 2002; Depowski et al.), language 
(Gallese, 2008; Myachykov and Tomlin, 2008; Myachykov et al., 2012; Lam et al.; Shaw and Bortfeld), embodied reasoning (Dumitru, 2014), sensory awareness (Cox and Hong), numerical cognition (Dumitru and Joergensen), auditory perception (Brogaard and Gatzia), and time perception (Homma and Ashida).

The articles included in this special issue offer novel insights about recent developments within the field of multisensory integration, and we believe that they will help understanding the multisensory nature of brain functioning.

\section{REFERENCES}

Amad, A., Cachia, A., Gorwood, P., Pins, D., Delmaire, C., Rolland, B., et al. (2014). The multimodal connectivity of the hippocampal complex in auditory and visual hallucinations. Mol. Psychiatry 19, 184-191. doi: 10.1038/mp. 2012.181

Anderson, M. L. (2010). Neural reuse: a fundamental organizational principle of the brain. Behav. Brain Sci. 33, 245-266. doi: 10.1017/S0140525X100 00853

Dumitru, M. L. (2014). Moving stimuli guide retrieval and (in)validation of coordination simulations. Cogn. Process. 15, 397-403. doi: 10.1007/s10339-0140604-6

Elliott, M. T., Wing, A. M., and Welchman, A. E. (2010). Multisensory cues improve sensorimotor synchronisation. Eur. J. Neurosci. 31, 1828-1835. doi: 10.1111/j.1460-9568.2010.07205.x

Ehrsson, H. H., Holmes, N. P., and Passingham, R. E. (2005). Touching a rubber hand: feeling of body ownership is associated with activity in multisensory brain areas. J. Neurosci. 25, 10564-10573. doi: 10.1523/JNEUROSCI.0800-05.2005

Farnè, A., Iriki, A., and Làdavas, E. (2005). Shaping multisensory action-space with tools: evidence from patients with cross-modal extinction. Neuropsychologia 43, 238-248. doi: 10.1016/j.neuropsychologia.2004.11.010

Fetsch, C. R., Pouget, A., DeAngelis, G. C., and Angelaki, D. E. (2012). Neural correlates of reliability-based cue weighting during multisensory integration. Nat. Neurosci. 15, 146-154. doi: 10.1038/nn.2983

Gallese, V. (2008). Mirror neurons and the social nature of language: the neural exploitation hypothesis. Soc. Neurosci. 3, 317-333. doi: 10.1080/17470910701563608

Ghazanfar, A. A., and Schroeder, C. E. (2006). Is neocortex essentially multisensory? Trends Cogn. Sci. 10, 278-285. doi: 10.1016/j.tics.2006.04.008

Gobbelé, R., Schürmann, M., Forss, N., Juottonen, K., Buchner, H., and Hari, R. (2003). Activation of the human posterior parietal and temporoparietal cortices during audiotactile interaction. Neuroimage 20, 503-511. doi: 10.1016/S10538119(03)00312-4

Green, A. M., and Angelaki, D. E. (2010). Multisensory integration: resolving sensory ambiguities to build novel representations. Curr. Opin. Neurobiol. 20, 353-360. doi: 10.1016/j.conb.2010.04.009

Kuraoka, K., and Nakamura, K. (2007). Responses of single neurons in monkey amygdala to facial and vocal emotions. J. Neurophysiol. 97, 1379-1387. doi: 10.1152/jn.00464.2006

Murray, M. M., Molholm, S., Michel, C. M., Heslenfeld, D. J., Ritter, W., Javitt, D. C., et al. (2005). Grabbing your ear: Rapid auditory-somatosensory multisensory interactions in low-level sensory cortices are not constrained by stimulus alignment. Cereb. Cortex 15, 963-974. doi: 10.1093/cercor/bhh197

Myachykov, A., and Tomlin, R. (2008). Perceptual priming and syntactic choice in Russian sentence production. J. Cogn. Sci. 9, 31-48. doi: $10.17791 /$ jcs.2008.9.1.31

\section{AUTHOR CONTRIBUTIONS}

AP wrote the first draft of the manuscript. MD and AM provided comments, additions, and further improvements. All authors have approved the final version of the manuscript.

\section{ACKNOWLEDGMENTS}

MD was supported by a Marie Curie FP7-PEOPLE-IAPP fellowship (grant number 610986).

Myachykov, A., Garrod, S., and Scheepers, C. (2012). Determinants of structural choice in visually-situated sentence production. Acta Psychol. 141, 304-315. doi: 10.1016/j.actpsy.2012.09.006

Pascual-Leone, A., and Hamilton, R. (2001). The metamodal organization of the brain. Prog. Brain Res. 134, 427-445. doi: 10.1016/S0079-6123(01)34028-1

Pasqualotto, A., Finucane, C. M., and Newell, F. N. (2005). Visual and haptic representations of scenes are updated with observer movement. Exp. Brain Res. 166, 481-488. doi: 10.1007/s00221-005-2388-5

Pasqualotto, A., and Proulx, M. J. (2012). The role of visual experience for the neural basis of spatial cognition. Neurosci. Biobehav. Rev. 36, 1179-1187. doi: 10.1016/j.neubiorev.2012.01.008

Pasqualotto, A., and Proulx, M. J. (2015). Two-dimensional rubber-hand illusion: the Dorian Gray hand illusion. Multisens. Res. 28, 101-110. doi: 10.1163/22134808-00002473

Pietrini, P., Furey, M. L., Ricciardi, E., Gobbini, M. I., Wu, W. H. C., Cohen, L. G., et al. (2004). Beyond sensory images: object-based representation in the human ventral pathway. Proc. Natl. Acad. Sci. U.S.A. 101, 5658-5663. doi: 10.1073/pnas.0400707101

Sarno, S., Erasmus, L. P., Lipp, B., and Schlaegel, W. (2003). Multisensory integration after traumatic brain injury: a reaction time study between pairings of vision, touch and audition. Brain Inj. 17, 413-426. doi: 10.1080/0269905031000070161

Sereno, M. I., and Huang, R. S. (2006). A human parietal face area contains aligned head-centered visual and tactile maps. Nat. Neurosci. 9, 1337-1343. doi: $10.1038 / \mathrm{nn} 1777$

Spence, C. (2002). Multisensory attention and tactile information-processing. Behav. Brain Res. 135, 57-64. doi: 10.1016/S0166-4328(02)00155-9

Stein, B. E., and Meredith, M. A. (1993). The Merging of the Senses. Boston, MA: The MIT Press.

Woods, A. T., and Newell, F. N. (2004). Visual, haptic and crossmodal recognition of objects and scenes. J. Physiol. 98, 147-159. doi: 10.1016/j.jphysparis.2004.03.006

Zangaladze, A., Epstein, C. M., Grafton, S. T., and Sathian, K. (1999). Involvement of visual cortex in tactile discrimination of orientation. Nature 401, 587-590. doi: $10.1038 / 44139$

Conflict of Interest Statement: The authors declare that the research was conducted in the absence of any commercial or financial relationships that could be construed as a potential conflict of interest.

Copyright (c) 2016 Pasqualotto, Dumitru and Myachykov. This is an open-access article distributed under the terms of the Creative Commons Attribution License (CC $B Y)$. The use, distribution or reproduction in other forums is permitted, provided the original author(s) or licensor are credited and that the original publication in this journal is cited, in accordance with accepted academic practice. No use, distribution or reproduction is permitted which does not comply with these terms. 